Research

\title{
Role of 18F-PET-CT to predict pathological response after neoadjuvant treatment of rectal cancer
}

\author{
Riccardo Caruso ${ }^{1}$ (D Emilio Vicente ${ }^{1} \cdot$ Yolanda Quijano $^{1} \cdot$ Hipolito Duran ${ }^{1} \cdot$ Isabel Fabra $^{1} \cdot$ Eduardo Diaz $^{1}$. \\ Luis Malave $^{1} \cdot$ Ruben Agresott $^{1} \cdot$ Lina García Cañamaque $^{2} \cdot$ Benedetto lelpo $^{3} \cdot$ Valentina Ferri $^{1}$
}

Received: 5 January 2021 / Accepted: 12 March 2021

Published online: 18 May 2021

(c) The Author(s) 2021 OPEN

\begin{abstract}
Objectives Neoadjuvant chemoradiation (nCRT) is universally considered to be a valid treatment to achieve downstaging, to improve local disease control and to obtain better resectability in locally advanced rectal cancer (LARC). The aim of this study is to correlate the change in the tumour 18F-FDG PET-CT standardized uptake value (SUV) before and after $n C R T$, in order to obtain an early prediction of the pathologic response $(p R)$ achieved in patients with LARC.

Data description We performed a retrospective analysis of patients with LARC diagnosis who underwent curative resection. All patients underwent a baseline 18F-FDG PET-CT scan within the week prior to the initiation of the treatment (PET-CT SUV1) and a second scan (PET-CT SUV2) within 6 weeks of the completion of $n C R T$. We evaluated the prognostic value of 18F-FDG PET-CT in terms of disease-free survival (DFS) and overall survival (OS) in patients with LARC.A total of 133 patients with LARC were included in the study. Patients were divided in two groups according to the TRG (tumour regression grade): 107 (80\%) as the responders group (TRG0-TRG1) and $26(25 \%)$ as the no-responders group (TRG2TRG3). We obtained a significant difference in $\triangle \%$ SUV between the two different groups; responders versus no-responders $(p<0.012)$. The results of this analysis show that 18F-FDG PET-CT may be an indicator to evaluate the $p R$ to $n C R T$ in patients with LARC. The decrease in 18F-FDG PET-CT uptake in the primary tumour may offer important information in order for an early identification of those patients more likely to obtain a PCR to nCRT and to predict those who are unlikely to significantly regress.
\end{abstract}

\section{Introduction}

Nowadays neoadjuvant chemoradiation ( $\mathrm{nCRT}$ ) is universally considered to be a valid treatment to achieve downstaging, to improve local disease control and to obtain better resectability in locally advanced rectal cancer (LARC) [1]. Currently, about $15-30 \%$ of patients undergoing neoadjuvant treatment achieve a pathologic complete response (pCR) with improved oncological outcomes [2]. A major challenge for the surgeon is to determine the course of treatment for those patients with pCR after nCRT [3-5]. In fact, the difficult choice between surgery (radical rectal resection or transanal local excision of the residual scar) and the 'wait-and-see' strategy does not provide a definitive or widely-applicable answer. The $\mathrm{PCR}$ is defined through endoscopy with biopsy and through radiological studies. However, a more reliable

$\triangle$ Riccardo Caruso, ricaruso2@gmail.com; Emilio Vicente, correo@emiliovicente.es; Yolanda Quijano, yolandaquijanocollazo@ gmail.com; Hipolito Duran, hduran@hmhospitales.com; Isabel Fabra, isafabra@gmail.com; Eduardo Diaz, ediaz@hmhospitales.com; Luis Malave, malavecardozol@gmail.com; Ruben Agresott, rubendagresottm@gmail.com; Lina García Cañamaque, Igarciacanamaque@ hmhospitales.com; Benedetto lelpo, ielpo.b@gmail.com; Valentina Ferri, valenpeglio@gmail.com | ${ }^{1}$ General Surgery Department, Sanchinarro University Hospital, San Pablo University, CEU, C/Oña No. 10, 28050 Madrid, Spain. ${ }^{2}$ Division of Nuclear Medicine, Sanchinarro Hospital, San Pablo University, Madrid, Spain. ${ }^{3} \mathrm{HPB}$ Unit, University Parc Salut Mar Hospital, Barcelona, Spain.

Discover Oncology (2021) 12:16 | |https://doi.org/10.1007/s12672-021-00405-w 
histopathologic response is obtained only after the resected specimen analysis [6, 7]. For this reason, it is important to develop methods to identify an early prediction of histopathological response in patients with LARC after nCRT. The early determination of pathological response to $\mathrm{nCRT}$ is important not only for prognostic value but also to change or adapt the standard nCRT strategy for those patients with a suboptimal pathologic response [8]. At this time, 18F-FDG $\mathrm{PET}-\mathrm{CT}$ is one of the most powerful tools in cancer diagnosis and staging. It combines a positron emission tomography scanner (PET) and an X-ray computed tomography (CT) scanner, so that images acquired from both devices can be taken sequentially. The spatial distribution of metabolic or biochemical activity in the body can be more precisely aligned or correlated with anatomic imaging obtained by $\mathrm{CT}$ scanning. It is well known that $\mathrm{nCRT}$ induces changes in tumour metabolism that influence the 18F-FDG PET-CT tumour uptake [9].

\section{Materials and methods}

\subsection{Patient population}

We performed a retrospective analysis of patients with LARC diagnosis who underwent curative resection. The study was carried out at the General Surgery Department of the Sanchinarro University Hospital, Madrid, recruiting patients between October 2011 and February 2020 with LARC. The LARC patients are defined using radiological staging T3-4 e/o $\mathrm{N}+$ rectal tumour with a distance from the anal verge $\leq 10 \mathrm{~cm}$. Patients who are younger than 18 years old, with concomitant metastases, perforated tumours, peritoneal carcinomatosis or comorbidities precluding surgery and neoadjuvant therapy with rectal stent, are excluded from the analysis. All included patients received $\mathrm{nCRT}$, and surgical treatment was carried out 8-12 weeks after completing the neoadjuvant treatment. The preoperative study included a colonoscopy with biopsy to confirm rectal adenocarcinoma. Trans-anal endorectal ultrasound, pelvic MRI (magnetic resonance imaging), total body CT scan, and PET-CT scan were used as diagnostic and staging procedures. For the tumoral stage, the TNM staging system was used (American Joint Committee on Cancer) [10].

Pathologic tumour staging of the specimen after nCRT (ypTNM) and tumour regression grade (TRG) scores of the surgical specimens were established using the Seventh Guidelines of the American Joint Committee on Cancer [11]. TRG0 indicates a pathological complete response, TRG1 (moderate response) consists of single cells or small groups of cancer cells, TRG2 (minimal response) indicates residual cancer outgrown by fibrosis, and TRG3 (poor response) shows extensive residual cancer. Circumferential resection margin (CRM) is considered negative if the distance between the tumour and CRM is more than $1 \mathrm{~mm}$ [6]. Patients were divided into two groups according to the TRG: the responders group (TRG0TRG1) and the no-responders group (TRG2-TRG3). Furthermore, we evaluated the prognostic value of 18F-FDG PET-CT in terms of disease-free survival (DFS) and overall survival (OS) in patients with LARC. Following nCRT, patients were reassessed to evaluate the tumour's response 6 weeks after completing the treatment. The re-evaluation study included a full physical examination, MRI, CT-scan, and PET-CT scan. All resected specimens were examined by an experienced team of gastrointestinal pathologists. We excluded patients with stage IV and patients who were lost during follow up.

\subsection{Preoperative chemoradiation (nCRT)}

All patients were treated with preoperative intensity-modulated radiotherapy (IMRT) and an integrated-boost chemoradiation scheme. The planning target volume (PTV) included the presacral node, the tumour, the complete mesorectal fascia, and common and internal iliac lymph nodes. Radiation therapy was completed within 4-5 weeks, with a total of 23 fractions. The dose for the first PTV was $46 \mathrm{~Gy}$ in 23 fractions, and the concomitant boost (PTV2) was 57.5 Gy in 23 fractions ( $\mathrm{BED}=71.8 \mathrm{~Gy}[\mathrm{\alpha} / \beta=10]$ and $\mathrm{Eq} .2 \mathrm{~Gy} / \mathrm{f}=70 \mathrm{~Gy}$ ). All patients received concurrent standard capecitabine-based chemotherapy $\left(825 \mathrm{mg} / \mathrm{m}^{2}\right.$, in bid) and a blood count was performed every 14 days. None of the patients included in the study received a short-course of CRT. All patients underwent a surgical procedure, including a low anterior resection or abdominoperineal excision 6-8 weeks after the completion of treatment. All patients were operated on by the same team of surgeons and with mechanical bowel preparation. Our study adhered to the STROBE recommendation for observational studies. 


\subsection{F-FDG PET-CT analysis}

All patients underwent a baseline 18F-FDG PET-CT scan within the week prior to the initiation of the nCRT (PET-CT SUV1) and a second scan (PET-C T SUV2) within 6 weeks of the completion of nCRT. The 18F-FDG PET-CT was performed with the advance whole-body PET scanner in 3D mode, with axial spatial resolution of $4.7 \mathrm{~mm}$. CT-based attenuation and decay correction were done. Patients were fasting six hours before they underwent PET-CT, although water intake was encouraged. Before entering the scanner, patients were invited to drink water ( $1 \mathrm{l})$ and then void their bladder. Fasting serum glucose levels were checked $15 \mathrm{~min}$ before the FDG injection according to protocol. All patients received an intravenous injection of $18 \mathrm{~F}-\mathrm{FDG}$. The exact time of injection of $10-15 \mathrm{mCi}$ of $18 \mathrm{~F}-\mathrm{FDG}$ was recorded and imaging commenced no earlier than $45 \mathrm{~min}$ after the injection. Total body, caudo-cranial 18F-FDG PET-CT images were acquired $70 \mathrm{~min}$ after the injection of18F-FDG. PET-CT images were reconstructed from the acquired data, using the ordered subset expectation maximum iterative reconstruction algorithm. The maximum uptake value of the primary tumour was registered in all studies (baseline and after $\mathrm{n}$ weeks). SUVmax and SUVmean were calculated using the maximum and mean activity values with the highest radioactivity concentration in accordance with the injected dose and patient's body weight. Changes in SUVmax values were analysed as the percentage difference from 18F-FDG PET-CT 1 (before $\mathrm{nCRT})$ and 18F-FDG PET-CT 2 (after nCRT) $\left(\triangle \%\right.$ SUV $\left.=\left(\frac{\text { SUVpre-SUVpost }}{\text { SUVpre }} 100 \%\right)\right)$. It was evaluated in relation to the pathologic response, defined as the TRG [6].

\subsection{Statistical analysis}

Sensitivity, specificity, accuracy, positive predictive value (p-PV), and negative predictive value ( $n$-PV) of post nCRT 18F-FDG PET-CT were assessed. To compare the correlation between the quantitative (numerical) variables, when these followed a normal distribution, a variance analysis and a t-Student were used. Categorical variables were assessed using a Chi-square test. The Mann-Whitney U-Test and the Kruskal-Wallis test were performed for numerical variables. A receiver-operating characteristic $(\mathrm{ROC})$ curve and logistic regression techniques were used to obtain the predictive model and the inflection point. DFS and OS were calculated with the Kaplan-Meier method and log-rank test. A multivariate survival analysis for disease-free survival or overall survival was performed using the Cox proportional-hazard regression model. All variables related to the risk of DFS, or OS with a P value of $<0.2$ in univariate analysis, were included in the multivariate analysis. For the statistical analysis, SPSS software (version 10, IBM SPSS, Chicago, IL, USA) was used and all tests were considered statistically significant if the value of $p \leq 0.05$.

\subsubsection{Ethics}

The study was approved by the institutional ethical committee of Sanchinarro University Hospital, Madrid, and all patients included were informed about the treatment and provided written informed consent. The study was conducted in agreement with the Declaration of Helsinki for studies in humans.

\subsubsection{Study aims}

The aim of this study is to correlate the change in tumour 18F-FDG PET-CT standardized uptake value (SUV) before and after $\mathrm{nCRT}$ in patients with LARC, in order to differentiate between those who responded to treatment (the responders) and those who did not respond (the no-responders).

\section{Results}

A total of 137 patients with LARC were included and four were lost during follow-up as they underwent surgery in another centre and data could not be gathered. Therefore, 133 cases have been analysed (STROBE flowchart Fig. 1). The demographic data of the patients are summarized in Table 1. A total of 29 (22\%) patients underwent abdominoperineal excision of the rectum (APER), 90 (68\%) underwent a low anterior resection (LAR) with protective stoma and $14(10 \%)$ underwent a LAR without protective stoma, as shown in Table 2. Patients were divided in two groups according to the TRG: 107 (80\%) for the responders group (TRG0-TRG1) and 26 (25\%) the no-responders group 
Fig. 1 Flowchart

Table 1 Patients and tumor characteristics

Table 2 Operative data

Table 3 Evaluation of the tumor response (TRG score)

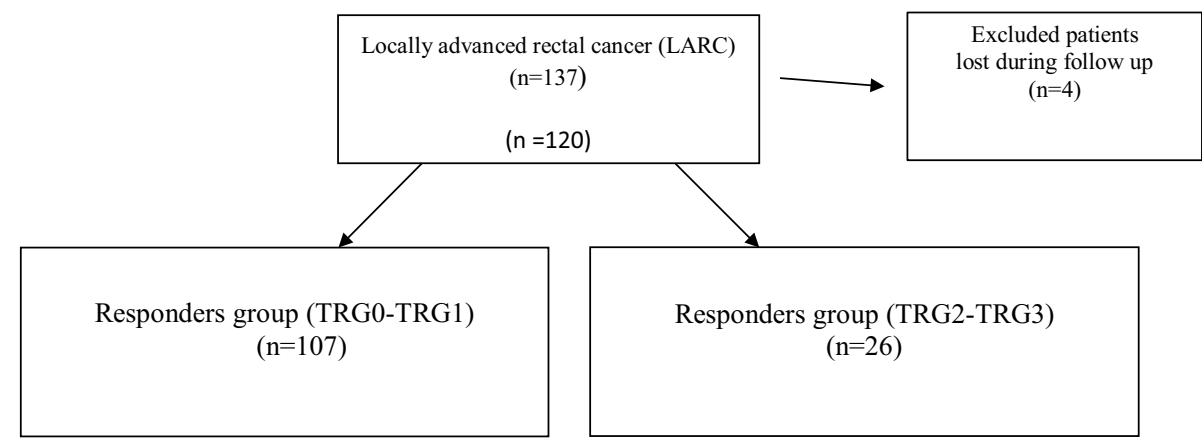

Median age (range)

$62.8(33-79)$

Sex

Male

$70(53 \%)$

Female

$63(47 \%)$

ASA

I

II

19 (14\%)

76 (57\%)

III

$38(29 \%)$

Clinical T stage

$100(75 \%)$

cT3

$33(25 \%)$

Clinical N stage

47 (36\%)

$67(50 \%)$

$19(14 \%)$

$\mathrm{cN} 2$

21 (16\%)

$77(58 \%)$

$35(26 \%)$

Type of resection

APER

LAR

LAR with stoma

$94(70 \%)$

Mean operative time (min) (SD)

$280 \pm 38$

Intraoperative blood (ml) (SD)

$205 \pm 26$

Hospital stay (days) (SD)

$12.42 \pm 7.77$

$A P E R$ abdominoperineal excision of the rectum, LAR low anterior resection, SD standard deviation

\begin{tabular}{|c|c|c|c|c|c|}
\hline & \multicolumn{4}{|l|}{ TRG } & \multirow[b]{2}{*}{ Total } \\
\hline & TRG 3 & TRG 2 & TRG 1 & TRG 0 & \\
\hline $\begin{array}{l}\text { Responders } \\
107(80 \%)\end{array}$ & $0(0)$ & $0(0)$ & $75(56)$ & $32(24)$ & $107(80)$ \\
\hline $\begin{array}{l}\text { No responders } \\
26(25 \%)\end{array}$ & $22(17)$ & $4(8)$ & $0(0)$ & (0) & $26(25)$ \\
\hline
\end{tabular}

TRG tumor regression grading 
Fig. 2 Difference in $\Delta \% S U V$ between the responders and no responders group
Fig. 3 ROC (receiver operating characteristic) curve
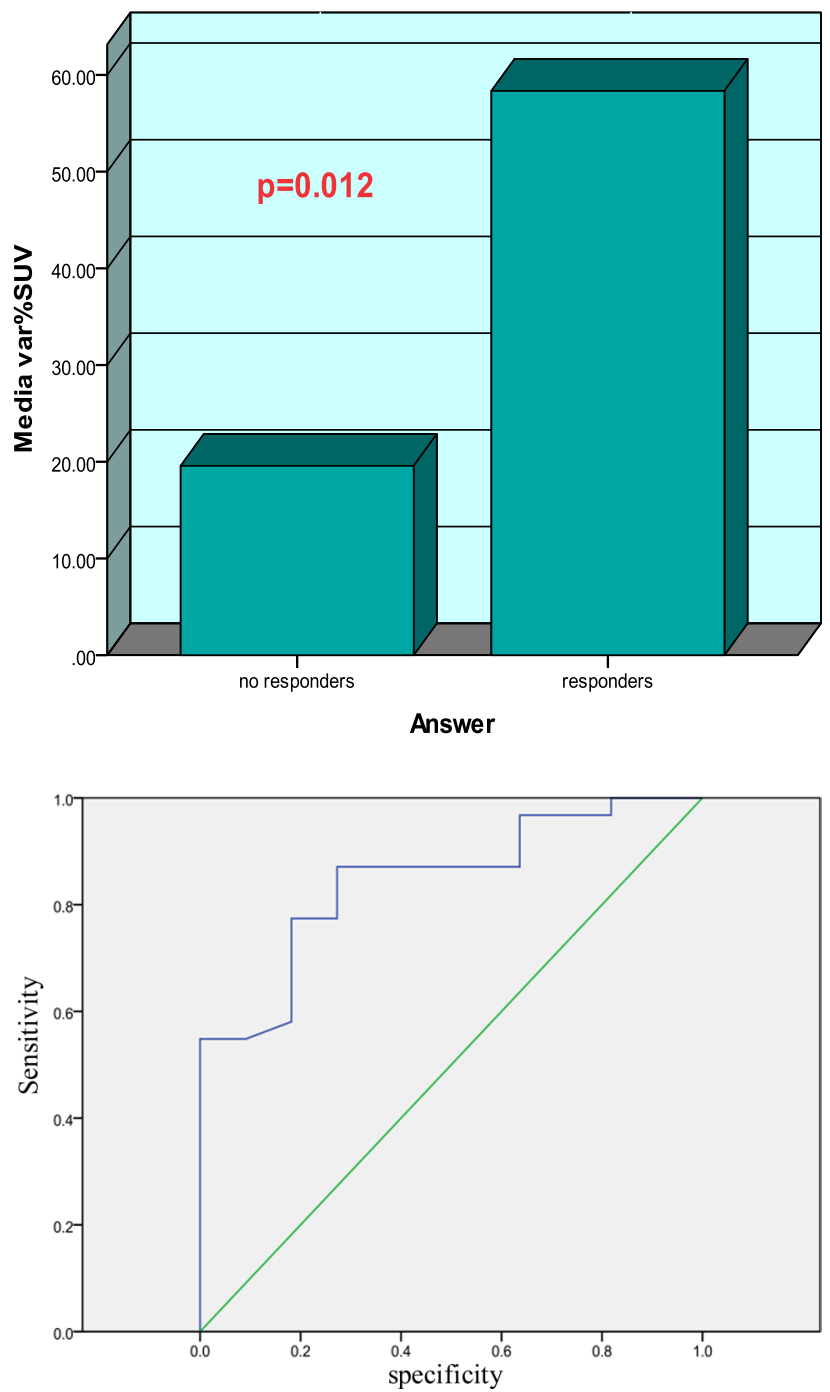

(TRG2-TRG3) (STROBE flowchart Fig. 1). Evaluation of the tumour response to $n C R T$ according to TRG score is shown in Table 3. We found a primary tumour downstaging in T classification after nCRT in 85 patients (65\%). Therefore, nodal downstaging after nCRT was achieved in 55 patients (42\%). In our series the pathological complete response $(\mathrm{cpR})$ rate was about $19 \%$. A logistic regression analysis was performed in order to obtain a prediction model of the tumour's pathological response (pR). Clinical prognostic factors (age, sex, TNM variables, tumoral markers, and FDG-PET values) were separately tested. From our statistical analysis, we obtained a significant difference in $\Delta \%$ SUV between the two groups, the responders ( $\Delta \%$ SUV $=58 \%)$ versus the no-responders ( $\Delta \%$ SUV $=19 \%)(p<0.012)$, as shown in Fig. 2. ROC curve preliminary cut-off value of $70 \%$ of the was individuate, as depicted in Fig. 3. This showed that $\triangle \%$ SUV media was a stronger discriminator between the two groups with a high accuracy of $81 \%(34 / 42)$, a sensitivity of $84.4 \%$, a specificity of $80 \%$, a positive predictive value of $81.4 \%(p-P V)$, and a negative predictive value of $84.2 \%$ (n-PV).

The median follow-up period was 60.54 months (a range of 9-103 months). Patients with overall recurrence totalled 25 (18.8\%) (three locoregional and 22 metastatic): 17 (12.8\%) patients with delta $\Delta \%$ SUV $<70 \%$ and 8 (6\%) patients with $\Delta \%$ SUV $>70 \%$ with a significant correlation between recurrence and $\Delta$ SUV $(p=0.037)$.

The median 5-years DFS was 55.3 months (a range of 9-92 months). In the group of patients with delta SUV $<70 \%$ DFS was $56.3 \%$ mean, while in patients with delta SUV $>70 \%$ DFS was $85.7 \%$, showing a statistical significance $(p<0.05)$ (Fig. 4).

In the multivariate analysis, $\triangle S U V$ results an independent risk factors, associated with local recurrence-free survival, as well as pTN stage and preoperative ASA (Table 4). 
Fig. 4 DFS (disease free survival) curve for the $\triangle$ SUV evaluation

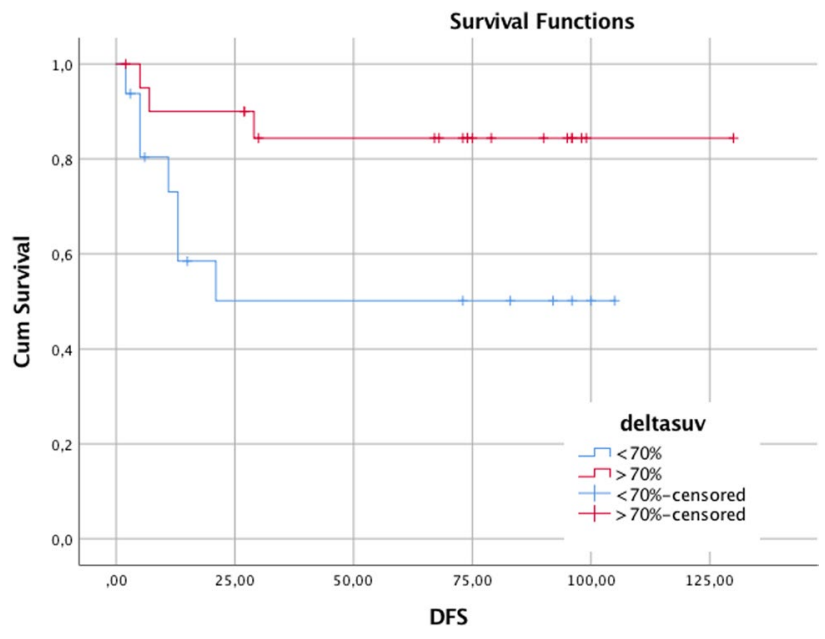

The 5 -years OS (overall survival) rate result was $60 \%$ in patients $\Delta \%$ SUV $<70 \%$ and $86.4 \%$ in patients $\Delta \%$ SUV $>70 \%$, showing a statistical significance $(p<0.05)$ (see Fig. 5). The unadjusted Cox-proportional hazards regression revealed that delta SUV and pTN were associated with worse overall survival (Table 5).

The datasets generated during and/or analysed during the current study are available from the corresponding author on reasonable request.

\section{Discussion}

Radical surgery with TME (total mesorectal excision) remains the main curative treatment for patients affected by LARC [12]. The TME associated with $\mathrm{nCRT}$ improve outcomes by increasing the 5-year survival rate [9]. Several previous studies have demonstrated that, compared with adjuvant treatment, preoperative nCRT significantly improves loco-regional tumour recurrence and reduces toxicity compared with postoperative strategies [10]. The early identification of $\mathrm{pR}$ after $\mathrm{nCRT}$ in rectal cancer remains an important challenge, and could avoid surgical overtreatment without compromising local control and long-term survival [12]. It could considerably reduce the number of surgical procedures required in the future, allowing less invasive procedures, such as TAMIS (trans-anal minimally invasive surgery), to be initially performed for LARC [3]. This latter approach could also reduce the rates of mortality, morbidity and other unsatisfactory functional outcomes that may occur after rectal resection. Furthermore, an early prediction in the no-responders group could provide the clinician the opportunity to evaluate the possibility of the reorientation of the standard treatment by also increasing the number of chemotherapy cycles and radiotherapy. The current conventional radiology, such as endorectal ultrasound (EU), CT scan and MRI for monitoring the tumour response, shows several limitations to assess the $\mathrm{pR}$ after $\mathrm{nCRT}$. This is mainly due to the difficulties in discerning between disease persistence and radiation induced inflammation and fibrosis after $\mathrm{nCRT}$ [13]. 18F-FDG PET-CT has a recognized validity for monitoring $n C R T$ effects [14-18].

There are several studies that have investigated the predictive value of $18 \mathrm{~F}-\mathrm{FDG}$ PET-CT in the LARC and in recurrent rectal cancer, and additional studies are likely to be conducted using collaborative, international research platforms [18-27]. However, these studies have some limits, mainly due to the methodological heterogeneity secondary to their multicentric nature in terms of preoperative studies, chemoradiotherapy, patients' characteristics and the PET study method (timing, technique and analysis of images). Despite these limits, it is important to note that almost all of these previous studies identify a significant correlation between tumour 18F-FDG uptake and pR, and a correlation between OS and DFS [13].

A recent study by Niccoli-Asabella et al. was able to evaluate the prognostic value of 18F-FDG PET-CT in terms of survival in patients with LARC who have undergone surgery after nCRT. This work showed a high percentage of patients with a TRG complete response (39.7\%) with longer OS and DFS in the Responders group but without statistically significant differences [13]. 
Table 4 Univariate and multivariate analysis DFS (disease free survival)

\begin{tabular}{|c|c|c|c|c|}
\hline \multirow[t]{2}{*}{ Variable } & \multicolumn{2}{|l|}{ Univariate analysis } & \multicolumn{2}{|l|}{ Multivariate analysis } \\
\hline & Hazard ratio & $\mathrm{p}$ values & Hazard ratio & $p$ values \\
\hline \multicolumn{5}{|l|}{ Age (years, SD) } \\
\hline $\begin{array}{l}<60 \\
>60\end{array}$ & $\begin{array}{l}1 \\
2.509(0.531-11.855)\end{array}$ & 0.224 & & \\
\hline \multicolumn{5}{|l|}{ Sex } \\
\hline $\begin{array}{l}F \\
M\end{array}$ & $\begin{array}{l}1 \\
0.850(0.246-2.941)\end{array}$ & 0.795 & & \\
\hline \multicolumn{5}{|l|}{ ASA } \\
\hline $\begin{array}{l}\text { I-II } \\
\text { III }\end{array}$ & $\begin{array}{l}1 \\
3.328(0.931-11.892)\end{array}$ & 0.064 & $\begin{array}{l}1 \\
5.074(1.086-23.710)\end{array}$ & 0.39 \\
\hline \multicolumn{5}{|l|}{ CEA } \\
\hline $\begin{array}{l}>5 \\
<5\end{array}$ & $\begin{array}{l}1 \\
1.706(0.340-4.067)\end{array}$ & 0.724 & & \\
\hline \multicolumn{5}{|c|}{ Tumor localization } \\
\hline $\begin{array}{l}>10 \mathrm{~cm} \\
<10 \mathrm{~cm}\end{array}$ & $\begin{array}{l}1 \\
1.007(0.278-14.172)\end{array}$ & 0.914 & & \\
\hline \multicolumn{5}{|l|}{ Approch } \\
\hline $\begin{array}{l}\text { Laparoscopic } \\
\text { Robotic }\end{array}$ & $\begin{array}{l}1 \\
2.297(0.487-10.830)\end{array}$ & 0.293 & & \\
\hline \multicolumn{5}{|l|}{ pTNM } \\
\hline $\begin{array}{l}0-1 \\
\|-I\end{array}$ & $\begin{array}{l}1 \\
3.717(0.786-17.569)\end{array}$ & 0.098 & $\begin{array}{l}1 \\
11.088(1.451-84.720)\end{array}$ & 0.20 \\
\hline \multicolumn{5}{|l|}{ TRG } \\
\hline $\begin{array}{l}0-1 \\
2-3\end{array}$ & $\begin{array}{l}1 \\
2.801(0.537-8.056)\end{array}$ & 0.268 & & \\
\hline \multicolumn{5}{|c|}{ Lymphonodal ratio } \\
\hline $\begin{array}{l}0 \\
<0.24 \\
>0.25\end{array}$ & $\begin{array}{l}1 \\
0.737(0.89-6.097) \\
0.717(0.64-8.064)\end{array}$ & 0.961 & & \\
\hline \multicolumn{5}{|l|}{ Blood trasfusion } \\
\hline $\begin{array}{l}\text { No } \\
\text { Yes }\end{array}$ & $\begin{array}{l}1 \\
3.120(0.866-11.239)\end{array}$ & 0.821 & $\begin{array}{l}1 \\
3.830(0.866-16.932)\end{array}$ & 0.077 \\
\hline \multicolumn{5}{|c|}{ Dindo-Clavien $\geq 3$} \\
\hline $\begin{array}{l}\text { No } \\
\text { Yes }\end{array}$ & $\begin{array}{l}1 \\
1.594(0.409-6.211)\end{array}$ & 0.542 & & \\
\hline \multicolumn{5}{|l|}{ SUV pre } \\
\hline $\begin{array}{l}<8 \\
>8\end{array}$ & $\begin{array}{l}1 \\
1.806(0.222-14.702)\end{array}$ & 0.572 & & \\
\hline \multicolumn{5}{|l|}{ SUV post } \\
\hline $\begin{array}{l}<8 \\
>8\end{array}$ & $\begin{array}{l}1 \\
2.090(0.535-8.166)\end{array}$ & 0.271 & & \\
\hline \multicolumn{5}{|l|}{$\triangle S U V$} \\
\hline $\begin{array}{l}<70 \% \\
>70 \%\end{array}$ & $\begin{array}{l}1 \\
4.078(1.046-15.900)\end{array}$ & 0.043 & $\begin{array}{l}1 \\
4.793(1.019-22.553)\end{array}$ & 0.047 \\
\hline \multicolumn{5}{|l|}{ CM affected } \\
\hline $\begin{array}{l}\text { Yes } \\
\text { No }\end{array}$ & $\begin{array}{l}1 \\
1.598(0.632-5.317)\end{array}$ & 0.954 & & \\
\hline
\end{tabular}

CM circumferencial margin 
Fig. 5 OS (overall survival) curve for the $\triangle$ SUV evaluation

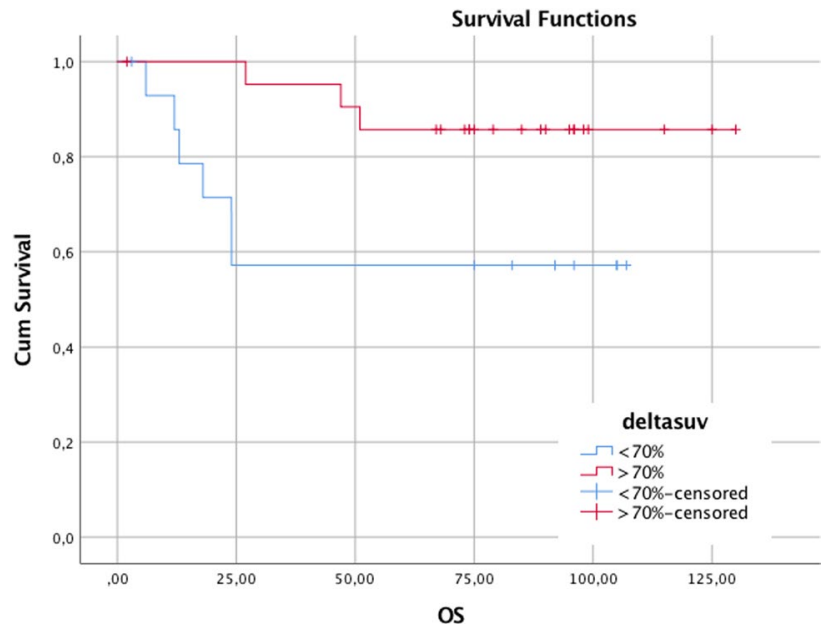

The strength of our study relies on being one of the largest studies evaluating 18F-FDG PET-CT related to histopathological response (TRG score) at two time-points: before $\mathrm{nCRT}$ (early PET-CT) and after finishing CRT (late PET/ $\mathrm{CT}$ ). We found the optimal cut-off to distinguish the responders (TRG3-TRG4) from the no-responders (TRG0-TRG2), at $70 \%$ of the $\Delta \%$ SUV. Furthermore, our analysis showed that $\triangle \%$ SUV was a stronger discriminator between the two groups with a high accuracy of $81 \%(34 / 42)$, with a sensitivity of $84.4 \%$, a specificity of $80 \%$, a positive predictive value of $81.4 \%$, and a negative predictive value of $84.2 \%$. We were able to find a correlation between $\triangle \% S U V$ and OS and DFS, also showing a statistical significance $(p<0.05)$.

Another similar study by Leccisotti et al. found similar results They learned that the optimal cut-off to distinguish the no-responders from the responders on the early PET-CT scan was a reduction in tumour SUVmax of $61.2 \%(85.4 \%$ sensitivity, $65.2 \%$ specificity) [18].

An important issue remains unclear; that is, the PET-CT study method (timing, technique, and qualitative analysis of images). Most studies report inaccurate results due to heterogeneous methods for 18F-FDG PET-CT quantification, the correct time to perform the study and the metabolic criteria $[19,20]$. It is important to standardize the criteria for the correct use of 18F-FDG PET-CT in order to achieve a correct interpretation of the results. In the current literature, there is no standardized data that indicates the proper timing by which to perform the 18F-FDG PET-CT. It is well known that chemotherapy produces an inflammatory reaction that lasts for one week after the beginning of treatment, while radiotherapy inflammatory reaction may last up to six months. Therefore, it is important choose or indicate the right time to perform 18F-FDG PET-CT after nCRT in order to standardize the correct interval as being a potential source of false-positive findings on the late 18F-FDG PET-CT. The World Health Organization recommends 18F-FDG PET-CT 7 weeks after $\mathrm{nCRT}$ and surgery one week later [28]. This is mainly based after the trial performed by R O Perez et al., showing a proper restaging with 18F-FDG PET-CT at 6 and 12 weeks after the completion of therapy [15]. The present study was concomitant with this recommendation, as all patients underwent FDG PET-CT 6-7 weeks after the end of nCRT, and surgery was performed 8 weeks from the end of neoadjuvant treatment.

The main limitations are the relatively small number of patients in our cohort due to a single centre enrolment. However, the unicentric nature of our study also represents a guarantee for more homogenous data.

We believe that more technically advanced tools are important to accurately measure tumour change. Nowadays the use of quantitative analysis of PET/MRI to assess PCR following $\mathrm{nRCT}$ in LARC could improve outcome predictions and may welcome the era of adaptive therapy for cancer patients [29, 30].

In conclusion, the results of this analysis are promising and show that 18F-FDG PET-CT may be an indicator to evaluate the $\mathrm{pR}$ to $\mathrm{nCRT}$ in patients with LARC. The decrease in 18F-FDG PET-CT uptake in the primary tumour may offer primary information for the early identification of patients who more likely to obtain a pCR to nCRT and to predict patients who are unlikely to significantly regress. Rigorous follow up and larger future prospective studies are necessary to confirm these results. 
Table 5 Univariate and multivariate analysis OS (overall survival)

\begin{tabular}{|c|c|c|c|c|}
\hline \multirow[t]{2}{*}{ Variable } & \multicolumn{2}{|l|}{ Univariate analysis } & \multicolumn{2}{|l|}{ Multivariate analysis } \\
\hline & Hazard ratio & $p$ values & Hazard ratio & $p$ values \\
\hline \multicolumn{5}{|l|}{ Age (years, SD) } \\
\hline $\begin{array}{l}<60 \\
>60\end{array}$ & $\begin{array}{l}1 \\
2.464(0.511-11.878)\end{array}$ & 0.261 & & \\
\hline \multicolumn{5}{|l|}{ Sex } \\
\hline $\begin{array}{l}F \\
M\end{array}$ & $\begin{array}{l}1 \\
1.472(0.395-5.486)\end{array}$ & 0.565 & & \\
\hline \multicolumn{5}{|l|}{ ASA } \\
\hline $\begin{array}{l}\text { I-II } \\
\text { III }\end{array}$ & $\begin{array}{l}1 \\
2.611(0.652-10.448)\end{array}$ & 0.175 & $\begin{array}{l}1 \\
4.851(0.752-21.283)\end{array}$ & 0.097 \\
\hline \multicolumn{5}{|l|}{ CEA } \\
\hline $\begin{array}{l}>5 \\
<5\end{array}$ & $\begin{array}{l}1 \\
1.102(0.296-4.107)\end{array}$ & 0.908 & & \\
\hline \multicolumn{5}{|c|}{ Tumor localization } \\
\hline $\begin{array}{l}>10 \mathrm{~cm} \\
<10 \mathrm{~cm}\end{array}$ & $\begin{array}{l}1 \\
1.133(0.283-4.533)\end{array}$ & 0.860 & & \\
\hline \multicolumn{5}{|l|}{ Approch } \\
\hline $\begin{array}{l}\text { Laparoscopic } \\
\text { Robotic }\end{array}$ & $\begin{array}{l}1 \\
4.921(0.615-39.385)\end{array}$ & 0.133 & $\begin{array}{l}1 \\
5.217 / 0.624-43.650)\end{array}$ & 0.127 \\
\hline \multicolumn{5}{|l|}{ PTNM } \\
\hline $\begin{array}{l}0-1 \\
\|-I 1\end{array}$ & $\begin{array}{l}1 \\
8.158(1.017-64.437)\end{array}$ & 0.048 & $\begin{array}{l}1 \\
15.315(1.550-151.339)\end{array}$ & 0.20 \\
\hline \multicolumn{5}{|l|}{ TRG } \\
\hline $\begin{array}{l}0-1 \\
2-3\end{array}$ & $\begin{array}{l}1 \\
2.126(0.531-8.504)\end{array}$ & 0.286 & & \\
\hline \multicolumn{5}{|c|}{ Lymphoonodal ratio } \\
\hline $\begin{array}{l}0 \\
<0.24 \\
>0.25\end{array}$ & $\begin{array}{l}1 \\
0.606(0.73-5.042) \\
0.634(0.57-7.000)\end{array}$ & 0,898 & & \\
\hline \multicolumn{5}{|c|}{ Blood trasfusion } \\
\hline $\begin{array}{l}\text { No } \\
\text { Yes }\end{array}$ & $\begin{array}{l}1 \\
2.065(0.515-8.280)\end{array}$ & 0.306 & & \\
\hline \multicolumn{5}{|c|}{ Dindo-Clavien > 3} \\
\hline $\begin{array}{l}\text { No } \\
\text { Yes }\end{array}$ & $\begin{array}{l}1 \\
1.093(0.227-5.268)\end{array}$ & 0.911 & & \\
\hline \multicolumn{5}{|l|}{ SUV pre } \\
\hline $\begin{array}{l}<8 \\
>8\end{array}$ & $\begin{array}{l}1 \\
1.728(0.212-14.056)\end{array}$ & 0.609 & & \\
\hline \multicolumn{5}{|l|}{ SUV post } \\
\hline $\begin{array}{l}<8 \\
>8\end{array}$ & $\begin{array}{l}1 \\
2.514(0.514-10.086)\end{array}$ & 0.271 & & \\
\hline \multicolumn{5}{|l|}{$\triangle \mathrm{SUV}$} \\
\hline $\begin{array}{l}<70 \% \\
>70 \%\end{array}$ & $\begin{array}{l}1 \\
4.060(1.010-16.319)\end{array}$ & 0.048 & $\begin{array}{l}1 \\
7.629(1.174-49.591)\end{array}$ & 0.033 \\
\hline \multicolumn{5}{|l|}{ CM affected } \\
\hline $\begin{array}{l}\text { Yes } \\
\text { No }\end{array}$ & $\begin{array}{l}1 \\
1.362(0.532-5.435)\end{array}$ & 0.834 & & \\
\hline
\end{tabular}

CM circumferencial margin

Acknowledgements The authors thank the International Department of Research in General and Digestive Surgery at the Catholic University of Murcia (Spain) Foundation for development and research in oncological surgery.

Authors' contributions EV and YQ proposed the study. RC performed the research and wrote the first draft with BL. VF collected and analyzed the data. All the authors contributed to the design and interpretation of the study and to further drafts. All authors agree with the content of the manuscript. All authors read and approved the final manuscript. We declare that this manuscript is original, has not been published before and is not currently being considered for publication elsewhere. 


\section{Declarations}

Competing interests The authors declare no competing interests.

Open Access This article is licensed under a Creative Commons Attribution 4.0 International License, which permits use, sharing, adaptation, distribution and reproduction in any medium or format, as long as you give appropriate credit to the original author(s) and the source, provide a link to the Creative Commons licence, and indicate if changes were made. The images or other third party material in this article are included in the article's Creative Commons licence, unless indicated otherwise in a credit line to the material. If material is not included in the article's Creative Commons licence and your intended use is not permitted by statutory regulation or exceeds the permitted use, you will need to obtain permission directly from the copyright holder. To view a copy of this licence, visit http://creativecommons.org/licenses/by/4.0/.

\section{References}

1. Li Yi, Wang Ji, Ma X, Tan Li, Yan Y, Xue C, Hui B, Liu R, Ma H, Ren J. A review of neoadjuvantchemoradiotherapy for locally advanced rectal cancer. Int J BiolSci. 2016;12(8):1022-31.

2. Niccoli-Asabella A, Altini C, De Luca R, Fanelli M, Rubini D. Prospective analysis of 18F-FDG PET/CT predictive value in patients with low rectal cancer treated with neoadjuvant chemoradiotherapy and conservative surgery. Biomed Res Int. 2014;2014:952843.

3. Luzietti E, Pellino G, Nikolaou S, Qiu S, Mills S, Warren O, Tekkis P, Kontovounisios C. Comparison of guidelines for the management of rectal cancer. BJS Open. 2018;2(6):433-51.

4. Pellino G, Warren O, Mills S, Rasheed S, Tekkis PP, Kontovounisios C. Comparison of Western and Asian guidelines concerning the management of colon cancer. Dis Colon Rectum. 2018;61(2):250-9.

5. Pellino G, Alós R, Biondo S, Codina-Cazador A, Enríquez-Navascues JM, Espín-Basany E, Roig-Vila JV, Cervantes A, García-Granero E, Spanish Rectal Cancer Project collaborators. Trends and outcome of neoadjuvant treatment for rectal cancer: a retrospective analysis and critical assessment of a 10-year prospective national registry on behalf of the Spanish Rectal Cancer Project. Eur J SurgOncol. 2020;S0748-7983(20):30454-6.

6. Franzè E, Dinallo V, Rizzo A, Di Giovangiulio M, Bevivino G, Stolfi C, Caprioli F, Colantoni A, Ortenzi A, Di Grazia A, Sica G, Sileri P, Rossi P, Monteleone G. Interleukin-34 sustains pro-tumorigenic signals in colon cancer tissue. Oncotarget. 2018;9(3):3432-45 (ISSN: 19492553).

7. De Simone V, Ronchetti G, Franzè E, Colantoni A, Ortenzi A, Fantini MC, Rizzo A, Sica GS, Sileri P, Rossi P, MacDonald TT, Pallone F, Monteleone G, Stolfi C. Interleukin-21 sustains inflammatory signals that contribute to sporadic colon tumorigenesis. Oncotarget. 2015;6(12):9908-23.

8. Avallone A, Aloj L, Pecori B, Caracò C, De Stefano A, Tatangelo F, Silvestro L, Granata V, Bianco F, Romano C, Di Gennaro F, Budillon A, Petrillo A, Muto P, Botti G, Delrio P, Lastoria S. (18)F-FDG PET/CT is an early predictor of pathologic tumor response and survival after preoperative radiochemotherapy with bevacizumab in high-risk locally advanced rectal cancer. J Nucl Med. 2019;60(11):1560-8.

9. Salih O, Cigdem S, Cihangir A, Nalan C. The role of $18 \mathrm{~F}$-fluorodeoxyglucose positron emission tomography/computed tomography in the primary staging of rectal cancer. World J SurgOncol. 2014;12:26.

10. Martin R, Weiser MD. AJCC 8th edition: colorectal cancer. AnnalSurgOncol. 2018;25:1454-5.

11. Weiser M. AJCC 8th edition: colorectal cancer. Ann SurgOncol. 2018;25:1454-5.

12. Fulong W, Wenhua F, Jianhong P, Zhenhai L, Zhizhong P, Liren L, Yuanhong G. Totalmesorectalexcision with or without preoperative chemoradiotherapy for resectable mid/low rectal cancer: a long-term analysis of a prospective, single-center, randomized trial. Cancer Commun (Lond). 2018;38:73.

13. Niccoli A, Simone M, Ballini A. Predictive value of $18 \mathrm{f}-\mathrm{fdg}$ pet/ct on survival in locally advanced rectal cancer afterneoadjuvant chemoradiation. Eur Rev Med PharmacologSci. 2018;22:8227-36.

14. Feeney G, Sehgal R, Sheehan M. Neoadjuvant radiotherapy for rectal cancer management. World J Gastroenterol. 2019;25(33):4850-69.

15. Perez RO, Habr-Gama A, São Julião GP, Lynn PB, Sabbagh C, Proscurshim I, Campos FG, Gama-Rodrigues J, Nahas SC, Buchpiguel CA. Predicting complete response to neoadjuvant CRT for distal rectal cancer using sequential PET/CT imaging. Tech Coloproctol. 2014;18(8):699-708.

16. Habr-Gama A, São Julião GP, Fernandez LM, Vailati BB, Andrade A, Araújo SEA, Gama-Rodrigues J, Perez RO. Achieving a complete clinical response after neoadjuvant chemoradiation that does not require surgical resection: it may take longer than you think! Dis Colon Rectum. 2019;62(7):802-8.

17. Kim JW, Kim HC, Park JW, Park SC, Sohn DK, Choi HS, Kim DY, Chang HJ, Baek JY, Kim SY, Kim SK. Predictive value of (18)FDG PET-CT for tumour response in patients with locally advanced rectal cancer treated by preoperative chemoradiotherapy. Int J Colorectal Dis. 2013;28(9):1217-24 (Epub 2013 Feb 13).

18. Leccisotti L, Gambacorta MA, de Waure C, Stefanelli A, Barbaro B, Vecchio FM, Coco C, Persiani R, Crucitti A, Tortorelli AP, Giordano A, Valentini V. The predictive value of $18 \mathrm{~F}-\mathrm{FDG}$ PET/CT for assessing pathological response and survival in locally advanced rectal cancer after neoadjuvant radiochemotherapy. Eur J Nucl Med Mol Imaging. 2015;42(5):657-66.

19. Murcia Duréndez MJ, Frutos Esteban L, Luján J, Frutos MD, Valero G, Navarro Fernández JL, Mohamed Salem L, Ruiz Merino G, Claver Valderas MA. The value of $18 \mathrm{~F}-\mathrm{FDG}$ PET/CT for assessing the response to neoadjuvant therapy in locally advanced rectal cancer. Eur J Nucl Med Mol Imaging. 2013;40(1):91-7.

20. Joye I, et al. The role of diffusion-weighted MRI and (18)F-FDG PET/CT in the prediction of pathologic complete response after radiochemotherapy for rectal cancer: a systematic review. RadiotherOncol. 2014;113:158-65.

21. Collaborative EuroSurg. EuroSurg: a new European student-driven research network in surgery. Colorectal Dis. 2016;18(2):214-5.

22. Petrelli F, Trevisan F, Cabiddu M, Sgroi G, Bruschieri L, Rausa E, Ghidini M, Turati L. Total neoadjuvant therapy in rectal cancer: a systematic review and meta-analysis of treatment outcomes. Ann Surg. 2020;271(3):440-8. 
23. Baird DLH, Kontovounisios C, Simillis C, et al. Factors associated with metachronous metastases and survival in locally advanced and recurrent rectal cancer. BJS Open. 2020;4(6):1172-9.

24. PelvEx Collaborative. Predicting outcomes of pelvic exenteration using machine learning. Colorectal Dis. 2020.

25. Pellino G, Biondo S, CodinaCazador A, Enríquez-Navascues JM, Espín-Basany E, Roig-Vila JV, García-Granero E. Rectal cancer project pelvic exenterations for primary rectal cancer: analysis from a 10-year national prospective database. World J Gastroenterol. 2018;24(45):5144-53.

26. Pellino G, Gallo G, Pallante P, Capasso R, De Stefano A, Maretto I, Malapelle U, Qiu S, Nikolaou S, Barina A, Clerico G, Reginelli A, Giuliani A, Sciaudone G, Kontovounisios C, Brunese L, Trompetto M, Selvaggi F. Noninvasive biomarkers of colorectal cancer: role in diagnosis and personalised treatment perspectives. Gastroenterol Res Pract. 2018;13(2018):2397863.

27. Selvaggi F, Fucini C, Pellino G, Sciaudone G, Maretto I, Mondi I, Bartolini N, Caminati F, Pucciarelli S. Outcome and prognostic factors of local recurrent rectal cancer: a pooled analysis of 150 patients. Tech Coloproctol. 2015;19(3):135-44.

28. Capirci C, Rampin L, Erba PA, Galeotti F, Crepaldi G, Banti E, et al. Sequential FDG-PET/CT reliability predicts response of locally advanced rectal cancer to neoadjuvant chemo-radiation therapy. Eur J Nucl Med Mol Imaging. 2007;34:1583-93.

29. Ferri V, Vicente E, Quijano Y, Caruso R, Duran H, lelpo B, Diaz Reques E. Quantitative analysis of 18-FDG-PET/MRI to assess pathological complete response following neoadjuvant radiochemotherapy in locally advanced rectal cancer. A prospective preliminary study. Acta Oncolog. https://doi.org/10.1080/0284186X.2019.1622774.

30. Amelio I, Bertolo R, Bove P, Candi E, Chiocchi M, Cipriani C, Di Daniele N, Ganini C, Juhl H, Mauriello A, Marani C, Marshall J, Montanaro M, Palmieri G, Piacentini M, Sica G, Tesauro M, Rovella V, Tisone G, Shi Y, Wang Y, Melino G. Cancer predictive studies. Biol Direct. 2020;15(1):18. https://doi.org/10.1186/s13062-020-00274-3. PMID: 33054808

Publisher's Note Springer Nature remains neutral with regard to jurisdictional claims in published maps and institutional affiliations. 